\title{
Correction to: Carbon Management for Promoting Local Livelihood in the Hindu Kush Himalayan (HKH) Region
}

Zhanhuan Shang, A. Allan Degen, Muhammad Khalid Rafiq, and Victor R. Squires

\section{Correction to:}

Z. Shang et al. (eds.), Carbon Management for Promoting

Local Livelihood in the Hindu Kush Himalayan (HKH) Region, https://doi.org/10.1007/978-3-030-20591-1

The original version of Chapters 1 and 18 was inadvertently published with incorrect affiliation of the author "Devendra Gauchan". This information has been updated as "Bioversity International, Lalitpur, Nepal".

The updated online versions of these chapters can be found at https://doi.org/10.1007/978-3-030-20591-1_1 